\title{
THE
}

\section{In Vitro and In Vivo Evidence for Lack of Endovascular Remodeling by Third Trimester Trophoblasts}

\author{
S. Kalkunte \\ Z. Lai \\ N. Tewari \\ Clinton O. Chichester III \\ University of Rhode Island, chichester@uri.edu \\ R. Romero
}

See next page for additional authors

Follow this and additional works at: https://digitalcommons.uri.edu/bps_facpubs

This is a pre-publication author manuscript of the final, published article.

Creative Commons License

(c) $($ ) $\Theta$

This work is licensed under a Creative Commons Attribution-Noncommercial-No Derivative Works 4.0 License.

\section{Citation/Publisher Attribution}

Kalkunte, S., Lai, Z., Tewari, N., Chichester, C., III, Romero, R., Padbury, J., \& Sharma, S. (2008). In Vitro and In Vivo Evidence for Lack of Endovascular Remodeling by Third Trimester Trophoblasts. Placenta, 29(10), 871-878. doi: 10.1016/j.placenta.2008.07.009

Available at: https://doi.org/10.1016/j.placenta.2008.07.009

This Article is brought to you for free and open access by the Biomedical and Pharmaceutical Sciences at DigitalCommons@URI. It has been accepted for inclusion in Biomedical and Pharmaceutical Sciences Faculty Publications by an authorized administrator of DigitalCommons@URI. For more information, please contact digitalcommons-group@uri.edu. 
Authors

S. Kalkunte, Z. Lai, N. Tewari, Clinton O. Chichester III, R. Romero, J. Padbury, and S. Sharma

This article is available at DigitalCommons@URI: https://digitalcommons.uri.edu/bps_facpubs/176 


\title{
In vitro and in vivo evidence for lack of endovascular remodeling by third trimester trophoblasts
}

\author{
Satyan Kalkunte ${ }^{1}$, Zhongbin Lai ${ }^{1}$, Neetu Tewari ${ }^{1}$, Clinton Chichester ${ }^{2}$, Roberto Romero ${ }^{3}$, \\ James Padbury ${ }^{1}$, and Surendra Sharma ${ }^{1,{ }^{*}}$ \\ ${ }^{1}$ Department of Pediatrics, Women and Infants Hospital- Warren Alpert Medical School of Brown \\ University, Providence, RI, USA \\ ${ }^{2}$ Department of Biomedical and Pharmaceutical Sciences, School of Pharmacy, University of \\ Rhode Island, Kingston, RI, USA
}

${ }^{3}$ Perinatology Research Branch, National Institute of Child Health and Human Development (NICHD), Wayne State University, Detroit, MI, USA

\begin{abstract}
The placental-decidual interaction through invading trophoblasts determines whether a physiological transformation of the uterine spiral arteries is established or not. Trophoblastorchestrated artery remodeling is central to normal placentation. Dysregulated uteroplacental interaction and vascular remodeling are thought to be associated with the molecular events underlying the pathology of late pregnancy anomalies including preeclampsia. Although the exact gestational age at which trophoblast invasion ceases is not known, it remains unclear whether late pregnancy trophoblasts retain the ability to transform the uterine arteries. Here, we have developed a dual cell, in vitro culture system that mimics the vascular remodeling events during normal pregnancy. We demonstrate that first and third trimester trophoblasts respond differentially to interactive signals from endothelial cells when cultured on matrigel. Term primary trophoblasts or immortalized third trimester extravillous TCL1 trophoblasts not only fail to respond to signals from endothelial cells but also inhibit endothelial cell tube formation. In contrast, HTR8 cells, representing a first trimester trophoblast cell line with invasive properties, undergo spontaneous migration and synchronize with the endothelial cells in a capillary network. This disparity in behavior was confirmed in vivo using a matrigel plug assay. Poor expression of VEGF C and VEGF receptors coupled with high E-cadherin expression by term primary trophoblasts and TCL1 cells contributed to their restricted interactive and migratory properties. We further show that the kinase activity of VEGF R2 is essential for proactive cross-talk by HTR8 cells. This unique behavior of first trimester trophoblasts in the presence of endothelial cells offers a potential approach to study cell-cell interactions and to decipher modulatory components in the serum samples from adverse pregnancy outcomes.
\end{abstract}

(C) 2008 Elsevier Ltd. All rights reserved.

*Corresponding Author: Department of Pediatrics, Women and Infants Hospital, 101, Dudley Street, Providence, Rhode Island, 02905, USA, Tel: 401-274-1122, ext. 8004; ssharma@wihri.org.

Publisher's Disclaimer: This is a PDF file of an unedited manuscript that has been accepted for publication. As a service to our customers we are providing this early version of the manuscript. The manuscript will undergo copyediting, typesetting, and review of the resulting proof before it is published in its final citable form. Please note that during the production process errors may be discovered which could affect the content, and all legal disclaimers that apply to the journal pertain. 


\section{Introduction}

Pregnancy triggers dynamic changes in the human endometrium that allow its optimal decidualization and functional interaction with invading trophoblasts [1]. These changes are characterized by the highly choreographed events of hormonal regulation, immune cell recruitment, and invasion of the decidua by trophoblasts. Extravillous trophoblast invasion is a hallmark of normal pregnancy. Its dysregulation is associated with poor spiral artery remodeling and multiple disorders including preeclampsia, intrauterine growth restriction (IUGR), and preterm labor or preterm PROM [2-5]. The process of spiral artery transformation into wider capacitance vessels allows increased blood flow and nutrients to the fetus [6,7]. Although the exact gestational age at which trophoblast remodeling of the spiral arteries occur and ceases is ambiguous, this dynamic window is believed to be between first and second trimesters. On the other hand, shallow trophoblast invasion is thought to result in deficient remodeling and ischemia at the maternal-fetal interface, causing release of a variety of inflammatory factors from the placenta which affects maternal vascular homeostasis [8].

Since preeclampsia, IUGR, preterm labor or preterm PROM are late pregnancy maladies, we have addressed in this study the question of why trophoblasts from third trimester do not overcome the invasive deficiency associated with these disorders. It is not clear whether third trimester trophoblasts retain the ability to invade the decidua and respond to trophic signals from their surroundings to transform spiral arteries. Previous studies from our laboratory have demonstrated that first trimester and third trimester trophoblasts differ in the production of inflammatory and anti-inflammatory cytokines with significant attenuation of IL-10 at term [9]. Coincidently, IL-10 has been shown to protect against macrophagemediated inhibition of trophoblast invasion [10]. It is then plausible that third trimester trophoblasts may be defective in migration and cell-cell interaction. Although recent studies have provided ample evidence for well choreographed interactions between resident endothelial cells, uterine NK ( $\mathrm{uNK}$ ) cells and first trimester trophoblasts [11,12,13], the molecular and biochemical signature features that distinguish third trimester trophoblasts need to be characterized.

We have utilized serum from normal pregnant women to impart physiological environment to promote interactions between immortalized first trimester (HTR8) and third trimester (TCL1) trophoblasts with extravillous trophoblast properties, term primary trophoblasts and endothelial cells. We hypothesized that in response to normal pregnancy serum (NPS), TCL1 cells or term primary trophoblasts would interact poorly with endothelial cells compared to first trimester HTR8 trophoblasts. In this study, we have used dual cell culture assays on matrigel to dissect the influence of endothelial cells in regulating trophoblast migration and invasion that closely mimic spiral artery remodeling. This study offers a robust approach to decipher biochemical components that are modified or uniquely expressed in non-invading third trimester trophoblasts.

\section{Materials and Methods}

\subsection{Serum Collection}

The use of human blood was approved by the Institutional Review Boards of Women and Infants Hospital of Rhode Island, USA and Linkoping University Hospital, Linkoping, Sweden. Informed consent was obtained from women with normal pregnancies between 3640 weeks of gestation. Blood samples $(9-10 \mathrm{ml}$ ) were centrifuged at $2700 \mathrm{rpm}$ for $10 \mathrm{~min}$ to obtain serum and aliquots were stored at $-80^{\circ} \mathrm{C}$ until further use. 


\subsection{Isolation of term primary trophoblasts}

Cytotrophoblasts were isolated from term placental tissue as previously described [9]. Placental tissue was digested with decreasing concentrations of trypsin-DNase 1 (trypsin, 1 $\mathrm{mg} / \mathrm{ml}$; and DNase, $1.5 \mathrm{mg} / \mathrm{ml}$ ) at least four times at $37^{\circ} \mathrm{C}$ for $20 \mathrm{~min}$ each. The cell mass collected was treated with a red blood cell 7.3) for $5 \mathrm{~min}$ at lysis buffer $\left(0.15 \mathrm{M} \mathrm{NH}_{4} \mathrm{Cl}, 1\right.$ $\mathrm{mM} \mathrm{KHCO}$, and $0.1 \mathrm{mM}$ EDTA (pH room temperature with constant shaking. Cytotrophoblasts isolated in this manner were stained for cytokeratins or CD45 (a marker for immunocytes) to confirm their purity (>95\%).

\subsection{Trophoblast cell lines and cell culture}

We used immortalized first trimester trophoblast cell lines HTR8 and Swan 71 with properties of invasive extravillous cytotrophoblasts, and the third trimester extravillous TCL1 cell line $[14,15,16]$. Both primary trophoblasts and cell lines were maintained in Roswell Park Memorial Institute (RPMI) 1640 media purchased from Gibco (Gaithersburg, MD, USA) supplemented with 10\% fetal bovine serum, 2mM L-glutamine (Gibco BRL), $100 \mathrm{U} / \mathrm{ml}$ penicillin (Gibco BRL) and $0.1 \mathrm{mg} / \mathrm{ml}$ streptomycin (Gibco BRL). Cell lines were grown to $\sim 80 \%$ confluence and all cells from limited passages were used in the study. Freshly isolated primary trophoblasts cultured overnight were used for the studies. Human umbilical cord endothelial cells (HUVEC) and human uterine endothelial cells (HUtEC) were obtained from Cambrex (East Rutherford, NJ, USA) and cultured in EBM-2 medium (Cambrex, East Rutherford, NJ, USA). All cells were maintained in standard culture conditions of $5 \% \mathrm{CO}_{2}$ at $37^{\circ} \mathrm{C}$.

\subsection{Three dimensional dual cell co-culture assay}

Growth factor-reduced Matrigel (BD Biosciences, San Diego, CA, USA) was thawed overnight at $4{ }^{\circ} \mathrm{C}$ and mixed to homogeneity. Culture plates (48-well) were coated with 0.1 $\mathrm{ml}$ of Matrigel and allowed to gelatinize at $37^{\circ} \mathrm{C}$ for $30 \mathrm{~min}$. Trophoblasts or endothelial cells $\left(2.5 \times 10^{4}\right)$, labeled with cell tracker green CMFDA or cell tracker orange CMTMR (Molecular Probes, Eugene, OR, USA), respectively, were singly cultured or co-cultured (1:1) in the presence of $10 \%$ normal pregnancy serum (NPS). The number and ratios of the trophoblasts and endothelial cells for optimal interaction was based on preliminary studies using different ratios of cells. The cellular interactions and endothelial cell-directed tube formation by trophoblasts were monitored and recorded after 10-12 hrs of incubation using the fluorescence microscopy ( $4 \times$ and 10× magnification, Nikon Eclipse TS 100 coupled with CCD camera). The average number of tubes/vacuoles formed was quantified by counting the number of vacuoles formed in four different fields, by two independent investigators. A total of 8 different NPS samples were tested.

\subsection{VEGF R2 kinase inhibitor SU1498}

HTR8 cells were incubated with SU1498 (Calbiochem, CA, USA), a potent and selective inhibitor of VEGF R2 kinase activity [17] at 10 or $20 \mathrm{uM}$ concentration, for six hours in presence of NPS. The cells were washed, labeled with cell tracker green, trypsinized and cocultured with endothelial cells (HUVEC or HUtEC) on matrigel and the tube formation was initiated with the addition of $10 \%$ NPS. The morphological changes observed were recorded as mentioned earlier.

\subsection{Reverse transcription-polymerase chain reaction (RT-PCR) assay}

Total RNA was isolated with RNeasy Kit (QIAGEN, CA, USA) according to the manufacture's protocol. $2 \mu \mathrm{g}$ of RNA was used for the first strand cDNA synthesis by Superscript III (Invitrogen). The primer sets for VEGF A, VEGF C, E-cadherin, and $\beta$-actin are as follows: the VEGF A, sense $5^{\prime}$-CTCACCAAGGCCAGCACATAGG-3' ${ }^{\prime}$ and anti- 
sense 5' -ATCTGGTTCCGAAAACCCTGAG-3' (291 bp product); VEGF C, sense 5' GTCTGTGTCCAGTGTAGATG- ${ }^{\prime}$ and anti-sense $5^{\prime}$-AGGTAGCTCGTGCTGGTGTT-3 (360 bp product); E-cadherin, sense $5^{\prime}$-TCC ATTTCTTGGTCTACGCC- $3^{\prime}$ and anti-sense $5^{\prime}$-CACCTTCAGCCAACC TGTTT-3' (530 bp product), and $\beta$-actin, sense $5^{\prime}$ TCGACAACGGCTCCGGCA-3' and anti-sense 5' -AAGGTGTGGTGCCAGATT-3' (239 bp fragment). All the PCR reactions were conducted using GenAmp 9600 PCR system (Perkin-Elmer, Norwalk, CT). The optimal RT-PCR conditions were standardized for each product. PCR products were separated by electrophoresis on $2 \%$ agarose gels and stained with ethidium bromide.

\subsection{ELISA}

Culture supernatant from trophoblast cell lines and primary trophoblasts $\left(1 \times 10^{6} / \mathrm{ml}\right)$ was collected 48hrs after plating. Concentrations of VEGF A, VEGF C, placenta growth factor (PLGF), soluble Flt-1 (sFlt-1) and soluble Endoglin (sEng) were measured in triplicate by ELISA (Quantikine Kits, R\&D System, Minneapolis, MN, USA) according to the manufacturers' instructions. The results were normalized to protein concentration and expressed in $\mathrm{ng} / \mathrm{ml}$. The intra- and inter-assay coefficients of variation were $<10 \%$.

\subsection{Flow cytometry analysis}

Cells were harvested, washed twice with PBS buffer containing $0.1 \%$ sodium azide and $1 \%$ BSA. Cells were incubated in dark at $4^{\circ} \mathrm{C}$ for 30 min with appropriate antibodies. If necessary, cells were washed, incubated with secondary antibody at $4^{\circ} \mathrm{C}$ for 30 minutes and resuspended in PBS buffer. A total of 10,000 events were recorded and analyzed using FACS Calibur ${ }^{\mathrm{TM}}$ and WinMidi software (Becton Dickinson). Negative controls were performed for each cell type by incubating the cells with isotype-matched control antibodies. The anti-human mouse mAbs used for this study were FITC-conjugated HLA G (MEM-G/9 Abcam) and integrins (23C6, BD Biosciences), APC-conjugated $\alpha_{\mathrm{v}} \beta_{3}$ CD31 (PECAM-1) (WM59, eBioscience), PE-conjugated VE-Cadherin (16B1 eBioscience), VEGF R1, VEGF R2 and VEGF R3 (R\&D VEGF receptor sampler kit). For E-cadherin, we used goat antihuman E-cadherin primary antibody (R\&D System Inc) followed by PE conjugated antigoat IgG (Jackson Lab).

\subsection{In vivo studies}

A modified in vivo matrigel plug assay was performed as previously described [12]. Briefly, a $600 \mu 1$ mixture of endothelial cells $\left(2 \times 10^{5}\right)$ and growth factor reduced-matrigel resuspended in $10 \%$ NPS were injected subcutaneously (s.c.) into nude mice that resulted in the formation of palpable plugs. One hour later, $7.5 \times 10^{5}$ trophoblast cells (HTR8 or TCL1) were injected at the rim of the matrigel plug. The matrigel plugs were excised 6 days post injection; the cells were isolated using cell recovery solution (BD Biosciences) and stained with HLA G monoclonal antibody to quantify the number of the invading trophoblasts by flow cytometry.

\subsection{Statistical analysis}

Statistical significance of experimental differences was assessed using Student's paired ttests. The differences were considered to be statistically significant when the $p$ value was < 0.05 . 


\section{Results}

\subsection{Endothelial cells but not trophoblasts form tube-like capillary structures on matrigel}

We examined the ability of endothelial and trophoblasts cells to form tube like capillary structures on matrigel. Endothelial cells (HUVEC or HUtEC) and first trimester HTR8 trophoblasts, third trimester TCL1 trophoblasts, or term primary trophoblasts were cultured independently on matrigel in the presence of NPS. Endothelial cells (panels a, b), but not trophoblasts (panels c-e), migrated, polarized, underwent cytoskeleton remodeling, branched and formed the classical capillary like tube formation (Fig. 1A). Under identical culture conditions, trophoblasts failed to form tube like structures even after $72 \mathrm{hr}$ of incubation in the presence of NPS and rather remained aggregated as lumps or acinar structures.

\subsection{First trimester and third trimester trophoblasts exhibit differential interaction with endothelial cells on matrigel}

To understand the interactions of endothelial cells and trophoblasts, we examined the response of trophoblasts to the presence of endothelial cells on matrigel in the presence of NPS. When co-cultured, first trimester trophoblast HTR8 cells spontaneously "fingerprinted" the capillary tube-like structures of HUtEC, (panel f, k) or HUVEC (panel g, i). Similar results were obtained with another first trimester extravillous trophoblast cell line Swan 71 (data not shown). Under identical conditions, third trimester TCL1 trophoblasts (panel h) or primary trophoblasts (panel i) failed to participate in the capillary tube formation (Fig 1A). On the contrary, these cells hindered the formation of tube structures by endothelial cells. This distinct and unique interaction of first trimester trophoblasts compared to term trophoblasts pointed to inherent differences in the expression of angiogenic factors and/or their receptors or the adhesion molecules that promote or retard cellular migration and interaction. The average number of vacuoles formed (indicated by bold arrow) during the interactions of trophoblasts with HUVEC or HUtEC cells were quantified and shown in Fig. 1B. Since HUtEC and HUVEC show similar behavior, further experiments were carried out with HUVEC.

\subsection{Differential expression of vascular endothelial growth factors in trophoblasts}

The important growth factors that are central to angiogenesis belong to the vascular endothelial growth factor (VEGF) family including VEGF A and VEGF C. We examined mRNA expression of VEGF A and VEGF C in endothelial cells, HTR8, TCL1 and term primary trophoblasts using semi-quantitative PCR. VEGF A was expressed in all three cell lines as well as primary trophoblasts. In contrast, VEGF C was highly expressed in first trimester HTR8 cells but not TCL1 cells or primary trophoblasts (Fig. 2A). Next, we examined the concentrations of angiogenic factors in conditioned media of trophoblast cells and HUVEC by ELISA. Only the first trimester HTR8 cells produced VEGF A and VEGF $\mathrm{C}$ in significant amounts. On the other hand, TCL1 and term primary trophoblasts produced only VEGF A at comparable levels to HTR8. PIGF was produced at low levels in all cells studied. However, PIGF was the prominent secreted angiogenic factor by HUVEC cells along with VEGF C and very low levels of VEGF A (Fig. 2B).

\subsection{Expression of anti-angiogenic factors sFlt-1 and sEng and lack of VEGF receptors regulate non interactive features of term trophoblasts}

Despite the production of VEGF A, TCL1 cells and term primary trophoblasts fail to participate in tube formation and block tube formation by endothelial cells. It is possible that these cells have been programmed to express anti-angiogenic factors such as sFlt-1 that can act as a decoy receptor for VEGF A, and soluble endoglin (sEng). These two biomarkers 
have been implicated in pre-eclampsia. Our data suggest that first trimester HTR8 cells did not produce sFlt-1 while sEng was secreted at low levels (Fig. 3A). Term primary trophoblasts secreted high amounts of sFlt- 1 and sEng comparable to those produced by endothelial cells. To our surprise, TCL1 cells did not intrinsically produce any significant levels of sFlt-1 and sEng. A lack of sFlt-1 and sEng production by TCL1 cells does not explain their poor participation in tube formation. It is possible that the block in interaction with endothelial cells in tube formation is displayed at the level of VEGF receptor expression.

Next, we examined by FACS analysis the surface expression of the VEGF receptors on endothelial cells and trophoblasts (Fig. 3B-C). VEGF A predominantly signals through VEGF R1 and VEGF R2, whereas VEGF C utilizes VEGF R2 and VEGF R3 for signaling. We found that TCL1 cells and term primary trophoblasts minimally express all the three VEGF receptors, implying that these cells are likely to be unresponsive to VEGFs and poor partners in endovascular remodeling. In contrast, first trimester HTR8 cells express VEGF R2 prominently, with moderate expression of VEGF R1 and VEGF R3. Likewise, HUVEC cells were shown to express high levels of VEGF R1 along with VEGF R2 and VEGF R3.

\subsection{E-cadherin is uniquely expressed in TCL1 cells and term primary trophoblasts}

Cadherin encoded by the CDH5 gene is a $\mathrm{Ca}^{2+}$ dependent cell-cell adhesion molecule. When expressed on epithelial cells, E-cadherin is thought to stabilize the epithelial architecture by preventing invasion and by regulating the differentiation into a non-invasive phenotype. On the other hand, endothelial cells preferentially express VE-cadherin, not HLA G or E-cadherin (Fig. 4A). Recent studies suggest that invading trophoblasts undergo phenotypic changes losing E-cadherin and acquiring VE-cadherin expression [18]. Thus, we examined the expression of E-cadherin and VE-cadherin on trophoblasts by FACS and semi-quantitative PCR (E-cadherin). We also compared HLA G expression. E-cadherin was expressed abundantly on TCL1 cells and term trophoblasts but not on HTR8 cells both at protein and at mRNA level (Fig. 4A-B). Although, the expression of HLA G, a putative extravillous marker of trophoblasts, was intense and comparable, the endovascular marker VE-cadherin was found to be poorly expressed on both first trimester and third trimester trophoblasts (Fig. 4A). Taken together, our results indicate that the extent of E-cadherin expression may guide the ability of trophoblast cells for migration and interaction with endothelial cells.

\subsection{Functional kinase activity of VEGF R2 is critical for endothelial cell-directed tube formation by first trimester HTR8 trophoblasts}

Since HTR8 cells dominantly express VEGF R2, we examined the effect of SU1498, a specific VEGF R2 kinase inhibitor, on their in vitro interaction with endothelial cells as described in Materials and Methods. In contrast to vehicle treated cells, HTR8 cells pretreated with SU1498 were detected at the branch points along the tubes, but did not "fingerprint" the endothelial tube structures (Fig. 5a-c), indicating that signaling through kinase activity of VEGF R2 is critical for the endothelial cell-trophoblast interaction, a process required for spiral artery remodeling.

\subsection{In vivo evidence for poor angiogenic potential of TCL1 trophoblasts}

The data in Fig. 1 clearly demonstrate that TCL1 cells or term primary trophoblasts fail to interact with endothelial cells in capillary tube formation. However, it is still possible that in vitro conditions influenced their behavior. To rule out this possibility, we took advantage of an in vivo assay that has been recently developed to study angiogenic properties of uterine NK cells [12]. In this assay, uNK cells when present in a matrigel plug attract trophoblast cells toward the plug. In our assay, we replaced uNK cells with HUVEC cells. Matrigel 
mixed with HUVEC cells (Fig. 6b, c, e) or matrigel without cells (Fig. 6a, d) was injected in nude mice as described in Materials and Methods. HTR8 (Fig. 6a, b) or TCL1 cells (Fig. 6d, e) resuspended in NPS were subsequently injected at the rim of the plug. Since HUVEC cells do not express HLA G, we can easily assay for HLA G positive HTR8 and TCL1 cells isolated from the matrigel plugs. As observed by FACS analysis (Fig. 6), only the first trimester HTR8 cells were able to significantly invade the matrigel plugs in response to the chemo-attracting signals from endothelial cells (Fig. 6b), while third trimester TCL1 cells failed to invade the plugs (Fig. 6e). These data also clearly suggest that HTR8 invasion was specifically triggered by HUVEC cells as no HTR8 cells migrated to matrigel plug if not mixed with HUVEC cells (Fig. 6a). To confirm an angiogenic interaction between endothelial cells and HTR8 cells, we targeted VEGF R2 activity on HTR8 cells. Thus, pretreatment of HTR8 cells with the specific VEGF R2 kinase inhibitor SU1498, abrogated the migratory response of these cells (Fig. 6c).

\section{Discussion}

Single cell capillary tube formation using endothelial cells on three dimensional matrices like collagen, fibronectin and matrigel has been used to study the processes involved in angiogenesis [19]. Using a co-culture of endothelial cells and trophoblasts in this matrigelbased culture system, we have developed an in vitro model that closely mimics the cell-cell interactions at the maternal-fetal interface. This system allows cells to display the phenotypic and morphological characteristics that they are likely to assume in vivo [19]. Several studies have suggested that gestational age-related presence of angiogenic factors, cytokines, and hormones in maternal serum reflects intrauterine milieu. [20-25]. Thus, serum can function as a "blueprint" for the events at the maternal-fetal interface.

In this study, endothelial cells, but not trophoblasts, typically formed tube-like capillary structures in response to normal pregnancy serum (NPS). This suggests that NPS provides physiologically relevant pregnancy-based factors which initiate interactions between cells and morphological transformation. In co-culture studies, while HTR8 trophoblasts with invading features were uniquely influenced by cues from endothelial cells and "fingerprinted" endothelial cell-guided tube formation, third trimester TCL1 trophoblasts and term primary trophoblasts failed to respond to either HUVEC or HUtEC endothelial cells. Further, HTR8 cells introduced into pre-formed endothelial capillary network assume tube like structures with faster kinetics and stabilized the endothelial cell architecture possibly reflecting the initial stages of vascular remodeling in the spiral arteries, which is in agreement with the findings of Aldo et al. [11]. Importantly, the ability of endothelial cells to influence and guide trophoblasts was confirmed in vivo by using matrigel plug assay. Only first trimester HTR8 trophoblasts not TCL1 trophoblasts or term primary trophoblasts were able to invade in response to the angiogenic cues from the plug-entrapped endothelial cells. These observations clearly imply that late pregnancy trophoblasts possibly undergo intrinsic programming to lose their invasive properties and cell-cell interactions.

What could be the intrinsic properties and mechanistic underpinnings that abrogate invasion and cell-cell interaction of third trimester trophoblasts? This biologically important difference between first trimester and late pregnancy trophoblasts does not appear to stem from differential expression of VE-cadherin, HLA G, av $\beta 3$, and PECAM-1, as these molecules are similarly expressed or not expressed between trophoblasts from different gestational age (integrin and PECAM data not shown). Although VE-cadherin, HLA G, av $\beta 3$, and PECAM-1 have been implicated in promoting trophoblast migration and invasiveness $[18,26,27]$, it is possible that they can be overtly compensated by modulation of other adhesion molecules and VEGF machinery on third trimester trophoblasts. 
Our findings indicate that VEGF $\mathrm{C}$ is a signature angiogenic molecule expressed and secreted by first trimester trophoblasts, but not TCL1 cells and term trophoblasts. Interestingly, there is a striking association between tumor cells that produce VEGF C and their invasive and metastatic potential [28]. Further, our findings support in part an earlier report that invading cytotrophoblasts release VEGF C and PIGF which are critical components to acquisition of the endovascular phenotype, uterine invasion and spiral artery modification [29]. The VEGF family of angiogenic factors mediate their action by signaling through their cognate receptors VEGF R1 (Flt-1), VEGF R2 (KDR/Flk-1), VEGF R3 (Flt-4) [30]. Our findings indicate that unlike first trimester trophoblasts, primary term trophoblasts and third trimester TCL1 cells expressed VEGF receptors poorly. While VEGF A predominantly acts on VEGF R1 and VEGF R2, VEGF C functions through VEGF R2 and VEGF R3. Increased expression of VEGF R1 that lacks the signal transducing kinasedomain is observed in PE placenta [31]. This indicates that these trophoblasts would not be able to respond to angiogenic cues from the surrounding cells and suggest the importance of kinase activity for intracellular signaling. Our data strongly support this notion because SU1498, a specific inhibitor of VEGF R2 kinase activity, blocked both in vivo and in vitro the response of HTR8 cells to migrate or to interact with endothelial cells. Our findings suggest that functional VEGF R2 is indispensable for an active trophoblast-endothelial crosstalk. Similar observations have been reported for endothelial cells in angiogenesis and tube formation [32].

Reduced placental expression of VEGF and PIGF are consistently observed in preeclampsia $[20,21,24,25,32]$. Further, preeclampsia is frequently accompanied by enhanced circulation and placental expression of sFlt-1, which acts as a decoy receptor titrating out VEGFs and PIGF $[21,22,25]$. In this study, we show that high levels of sFlt-1 are secreted by term trophoblasts, shifting the net balance to favor anti-angiogenic activity as demonstrated by inhibition of tube formation. This disruption was further accentuated by the secretion of five fold higher amounts of soluble endoglin as compared with sFlt-1 levels. The soluble form of endoglin (CD105), a co-receptor involved in TGF $\beta$ signaling is reported to enhance the anti-angiogenic effects of sFlt-1 [23]. In addition, it is possible that TCL1 cells and term trophoblasts uniquely produce other effector molecules such as TGF $\beta$ that inhibit formation of endothelial cell tube structures. HTR8 cells were shown to have no endogenous TGF $\beta$ activity [15] whereas term trophoblasts have been shown to produce much higher amounts of active TGF $\beta$ [33].

Down-regulation of E-cadherin expression is correlated with cell invasiveness particularly during early tumor progression. E-cadherin is known to maintain differentiation and to inhibit invasion [34]. In this regard, our findings of abundant expression of E-cadherin in third trimester TCL1 cells and term trophoblasts, in contrast to first trimester HTR8 cells point to its contribution to the differential interaction with endothelial cells. Likewise, epigenetic regulation of E-cadherin has been associated with migratory or non-migratory properties of the choriocarcinoma cell line, BeWo [35]. The BeWo cells intrinsically do not express E-cadherin, but acquire it after treatment with 5-aza-2' ${ }^{\prime}$-deoxycytidine (5-AZA), an inhibitor of DNA methylation. Unlike choriocarcinoma BeWo cells, HTR8 cells did not change their properties after treatment with 5-AZA (data not shown), suggesting that lack of E-cadherin expression in HTR8 cells is not under the epigenetic regulation. However, the results with BeWo cells support our findings on the role of E-cadherin in TCL1 cells or term primary trophoblasts.

In summary, our findings strongly suggest that late pregnancy trophoblasts fail to participate in endovascular remodeling due to poor expression of VEGF C and VEGF R2, elevated production of anti-angiogenic factors, and robust expression of E-cadherin. Our findings suggest that extravillous trophoblasts from late pregnancy cannot overcome shallow 
trophoblast invasion in late pregnancy as they fail to migrate and engage proactively with spiral artery endothelial cells. The disparate behavior of first and third trimester trophoblasts to the presence of endothelial cells can be exploited to decipher the important components in the serum samples from adverse pregnancy outcomes.

\section{Acknowledgments}

This work was supported in part by an NIH grant P20RR018728, a Subcontract WSU05056 under NICHD Contract \#N01-HD-2-3342, and Superfund Basic Research Program Award (P42ES013660) from the NIEHS.

\section{References}

1. Georgiades P, Ferguson-Smith AC, Burton GJ. Comparative developmental anatomy of the murine and human definitive placentae. Placenta. 2002; 23:3-19. [PubMed: 11869088]

2. Pijnenborg R, Bland JM, Robertson WB, Brosens I. Uteroplacental arterial changes related to interstitial trophoblast migration in early human pregnancy. Placenta. 1983; 4:397-14. [PubMed: 6634666]

3. Naicker T, Khedun SM, Moodley J, Pijnenborg R. Quantitative analysis of trophoblast invasion in preeclampsia. Acta Obstet Gynecol Scand. 2003; 82:722-29. [PubMed: 12848643]

4. Espinoza J, Romero R, Mee Kim Y, Kusanovic JP, Hassan S, Erez O, et al. Normal and abnormal transformation of the spiral arteries during pregnancy. J Perinat Med. 2006; 34:447-58. [PubMed: 17140293]

5. Kim YM, Bujold E, Chaiworapongsa T, Gomez R, Yoon BH, Thaler HT, et al. Failure of physiologic transformation of the spiral arteries in patients with preterm labor and intact membranes. Am J Obstet Gynecol. 2003; 189:1063-69. [PubMed: 14586356]

6. Aplin J, Charlton S, Ayad S. An immunohistochemical study of human endometrial extracellular matrix during the menstrual cycle and first trimester of pregnancy. Cell Tissue Res. 1988; 253:23140. [PubMed: 3416340]

7. Kham EP, Gardner L, Loke YW, King A. The role of trophoblasts in the physiological change in decidual spiral arteries. Hum Reprod. 1999; 14:2131-38. [PubMed: 10438439]

8. Gilbert JS, Ryan MJ, LaMarca BB, Sedeek M, Murphy SR, Granger JP. Pathophysiology of hypertension during preeclampsia: linking placental ischemia with endothelial dysfunction. Am J Physiol Heart Circ Physiol. 2008; 294:541-50.

9. Hanna N, Hanna I, Hleb M, Wagner E, Dougherty J, Balkundi D, et al. Gestational age-dependent expression of IL-10 and its receptor in human placental tissues and isolated cytotrophoblasts. J Immunol. 2000; 164:5721-28. [PubMed: 10820249]

10. Renaud SJ, Postovit LM, Macdonald-Goodfellow SK, McDonald GT, Caldwell JD, Graham CH. Activated macrophages inhibit human cytotrophoblast invasiveness in vitro. Biol Reprod. 2005; 73:237-43. [PubMed: 15800179]

11. Aldo PB, Krikun G, Visintin I, Lockwood C, Romero R, Mor G. A novel three-dimensional in vitro system to study trophoblast-endothelium cell interactions. Am J Reprod Immunol. 2007; 58:98-110. [PubMed: 17631003]

12. Hanna J, Goldman-Wohl D, Hamani Y, Avraham I, Greenfield C, Natanson-Yaron S, et al. Decidual NK cells regulate key developmental processes at the human fetal-maternal interface. Nat Med. 2006; 12:1065-74. [PubMed: 16892062]

13. Greenwood JD, Minhas K, di Santo JP, Makita M, Kiso Y, Croy BA. Ultrastructural studies of implantation sites from mice deficient in uterine natural killer cells. Placenta. 2000; 21:693-02. [PubMed: 10985973]

14. Graham CH, Hawley TS, Hawley RG, MacDougall JR, Kerbel RS, Khoo N, et al. Establishment and characterization of first trimester human trophoblast cells with extended lifespan. Exp Cell Res. 1993; 206:204-11. [PubMed: 7684692]

15. Lewis MP, Clements M, Takeda S, Kirby PL, Seki H, Lonsdale LB, et al. Partial characterization of an immortalized human trophoblast cell-line, TCL-1, which possesses a CSF-1 autocrine loop. Placenta. 1996; 17:137-46. [PubMed: 8730883] 
16. Fest S, Brachwitz N, Schumacher A, Zenclussen ML, Khan F, Wafula PO, et al. Supporting the hypothesis of pregnancy as a tumor: survivin is upregulated in normal pregnant mice and participates in human trophoblast proliferation. Am J Reprod Immunol. 2008; 59:75-83. [PubMed: 18154598]

17. Boguslawski G, McGlynn PW, Harvey KA, Kovala AT. SU1498, an inhibitor of vascular endothelial growth factor receptor 2, causes accumulation of phosphorylated ERK kinases and inhibits their activity in vivo and in vitro. J Biol Chem. 2004; 279:5716-24. [PubMed: 14625306]

18. Bulla R, Villa A, Bossi F, Cassetti A, Radillo O, Spessotto P, et al. VE-cadherin is a critical molecule for trophoblast-endothelial cell interaction in decidual spiral arteries. Exp Cell Res. 2005; 303:101-13. [PubMed: 15572031]

19. Debnath J, Brugge JS. Modelling glandular epithelial cancers in three-dimensional cultures. Nat Rev Cancer. 2005; 5:675-88. [PubMed: 16148884]

20. Taylor RN, Grimwood J, Taylor RS, McMaster MT, Fisher SJ, North RA. Longitudinal serum concentrations of placental growth factor: evidence for abnormal placental angiogenesis in pathologic pregnancies. Am J Obstet Gynecol. 2003; 188:177-82. [PubMed: 12548214]

21. Levine RJ, Maynard SE, Qian C, Lim KH, England LJ, Yu KF, et al. Circulating angiogenic factors and the risk of preeclampsia. N Engl J Med. 2004; 350:672-83. [PubMed: 14764923]

22. Clark DE, Smith SK, He Y, Day KA, Licence DR, Corps AN, et al. A vascular endothelial growth factor antagonist is produced by the human placenta and released into the maternal circulation. Biol Reprod. 1998; 59:1540-48. [PubMed: 9828203]

23. Venkatesha S, Toporsian M, Lam C, Hanai J, Mammoto T, Kim YM, et al. Soluble endoglin contributes to the pathogenesis of preeclampsia. Nat Med. 2006; 12:642-49. [PubMed: 16751767]

24. Lindheimer MD, Romero R. Emerging roles of antiangiogenic and angiogenic proteins in pathogenesis and prediction of preeclampsia. Hypertension. 2007; 50:35-36. [PubMed: 17515451]

25. Chung JY, Song Y, Wang Y, Magness RR, Zheng J. Differential expression of vascular endothelial growth factor (VEGF), endocrine gland derived-VEGF, and VEGF receptors in human placentas from normal and preeclamptic pregnancies. J Clin Endocrin and Metab. 2004; 89:2484-90.

26. Zhau Y, Fisher SJ, Janatpor M, Genbacev O, Dejana E, Wheelock M, et al. Human cytotrophoblasts adopt a vascular phenotype as they differentiate. A strategy for successful endovascular invasion. J Clin Invest. 1997; 99:2139-51. [PubMed: 9151786]

27. Goldman-Who DS, Ariel I, Geenfield C, Hochner-Celnikier D, Cross J, Fisher S, et al. Lack of human leukocyte antigen-G expression in extravillous trophoblasts is associated with preeclampsia. Mol Hum Reprod. 2000; 6:88-95. [PubMed: 10611266]

28. Masatsugu Ueda M, Terai Y, Kumagai K, Ueki K, Yamaguchi H, Akise D, et al. Vascular endothelial growth factor $\mathrm{C}$ gene expression is closely related to invasion phenotype in gynecological tumor cells. Gynecol Oncol. 2001; 82:162-66. [PubMed: 11426979]

29. Zhou Y, Bellingard V, Feng KT, McMaster M, Fisher SJ. Human cytotrophoblasts promote endothelial survival and vascular remodeling through secretion of Ang2, PIGF, and VEGF-C. Dev Biol. 2003; 263:114-25. [PubMed: 14568550]

30. Hiratsuka S, Kataoka Y, Nakao K, Nakamura K, Morikawa S, Tanaka S, et al. Vascular endothelial growth factor A (VEGF-A) is involved in guidance of VEGF receptor-positive cells to the anterior portion of early embryos. Mol Cellular Biol. 2005; 25:355-63. [PubMed: 15601856]

31. Yang S, Xin X, Zlot C, Ingle G, Fuh G, Li B, et al. Vascular endothelial cell growth factor-driven endothelial tube formation is mediated by vascular endothelial cell growth factor receptor-2, a kinase insert domain-containing receptor. Arterioscler Thromb Vasc Biol. 2001; 21:1934-40. [PubMed: 11742867]

32. Zhou Y, McMaster M, Woo K, Janatpour M, Perry J, Karpanen T, et al. Vascular endothelial growth factor ligands and receptors that regulate human cytotrophoblast survival are dysregulated in severe preeclampsia and hemolysis, elevated liver enzymes, and low platelets syndrome. Am J Pathol. 2002; 160:1405-23. [PubMed: 11943725]

33. Karmakar S, Das C. Modulation of ezrin and E-cadherin expression by IL-1beta and TGF-beta1 in human trophoblasts. J Reprod Immunol. 2004; 64:9-29. [PubMed: 15596224]

34. D’Souza-Schorey C. Disassembling adherens junctions: breaking up is hard to do. Trends Cell Biol. 2005; 15:19-26. [PubMed: 15653074] 
35. Rahnama F, Shafiei F, Gluckman PD, Mitchell MD, Lobie PE. Epigenetic regulation of human trophoblastic cell migration and invasion. Endocrinology. 2006; 147:5275-83. [PubMed: $16887905]$ 

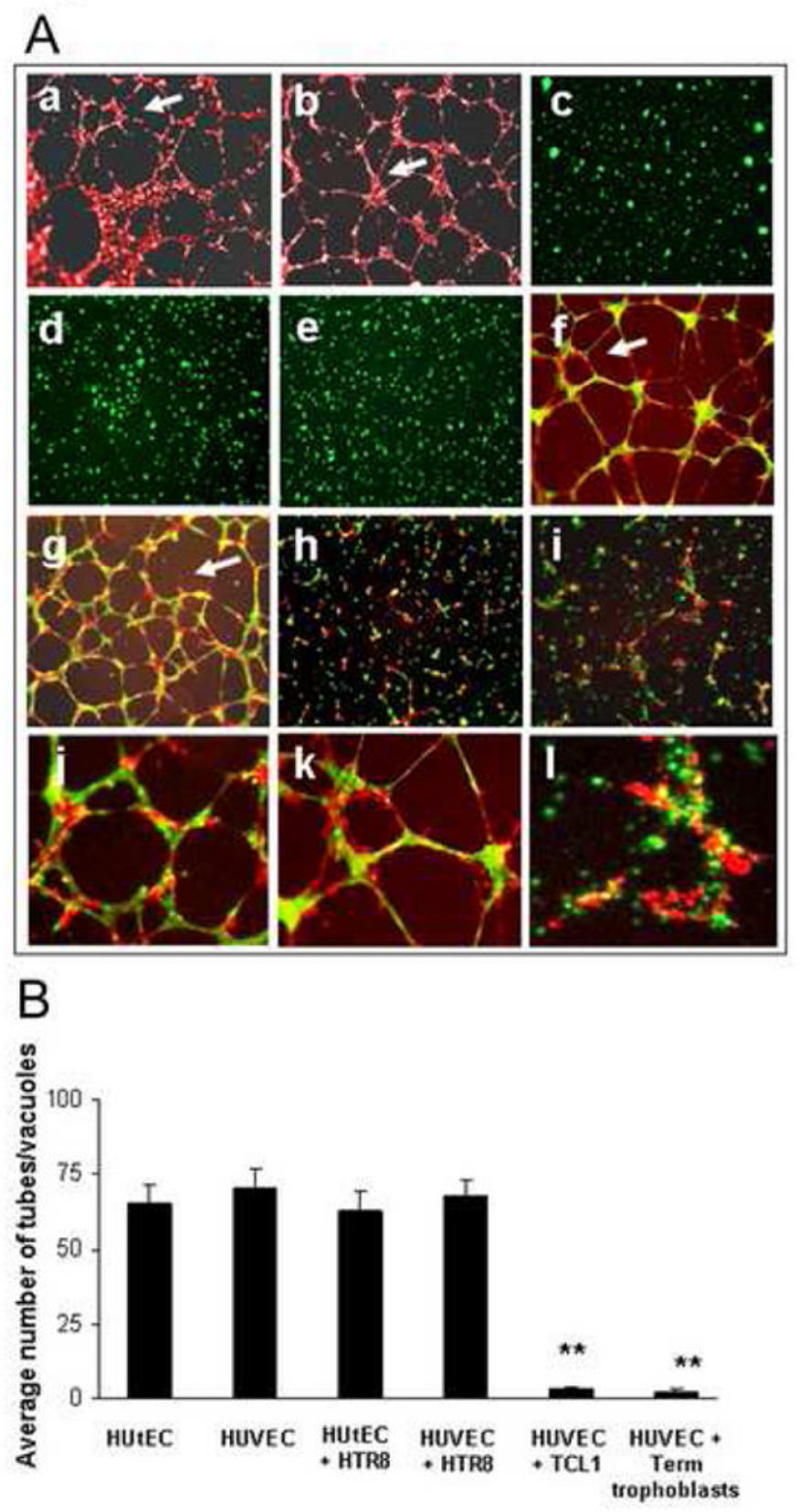

Figure 1. Representative photomicrographs of trophoblasts-endothelial cell interactions on matrigel

(A) Endothelial cells (EC) and trophoblasts cells, labeled with red and green cell tracker respectively, were independently $(\mathrm{a}-\mathrm{e})$ or co-cultured $(\mathrm{f}-\mathrm{i})$ on matrigel. Capillary like tube structures were observed for HUtEC (a) and HUVEC (b) endothelial cells (shown by bold arrow) but not for HTR8 (c), TCL1 (d), and term trophoblasts (e). However, in co-cultures, HTR8 "fingerprint" the HUtEC (f) or HUVEC (g) while TCL1 cells (h) and primary term trophoblasts (i) inhibited the tube formation by $\operatorname{HUVEC}(4 \mathrm{x}$, magnification). Panels $\mathrm{j}-1$ show co-cultures of HTR8 with HUVEC (j), HUtEC (k) and term trophoblasts with HUVEC (1) at higher magnification $(10 x)$. The panels are a representative of experiments in triplicate using 8 different NPS samples. 
(B) The average number of tubes/vacuoles formed was quantified in four different fields (4x, magnification). The numbers (bars, $+\mathrm{SD}$ ) are average of representative experiments (with six NPS samples) in triplicate, assessed by two independent investigators. ** $\mathrm{P}<0.05$ as compared to HUVEC+HTR8 group. 

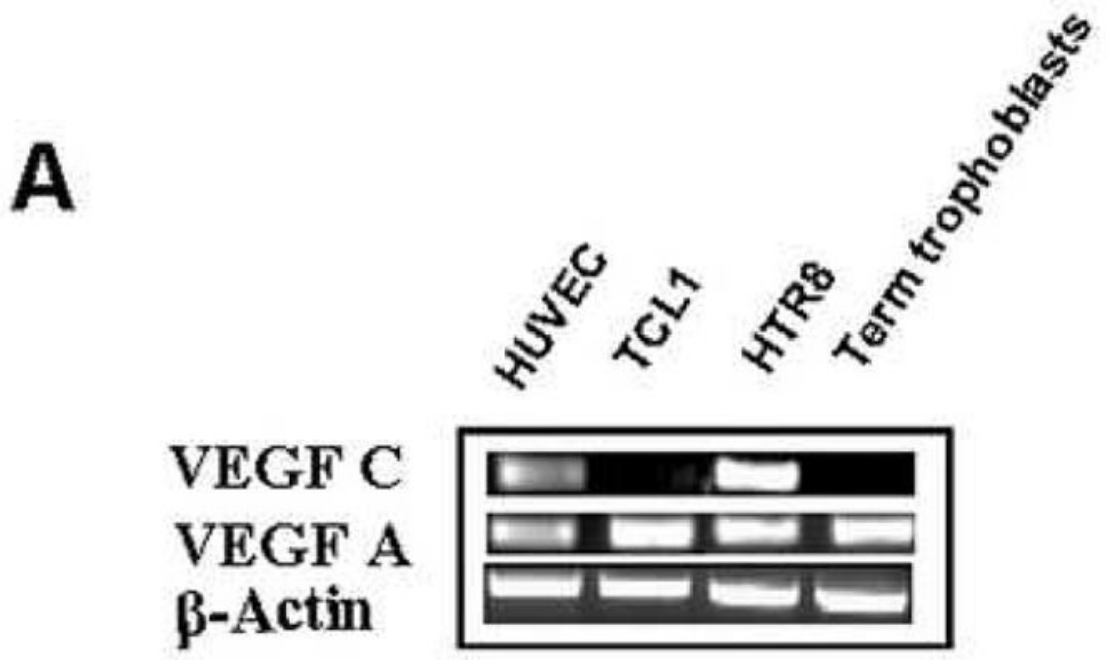

B

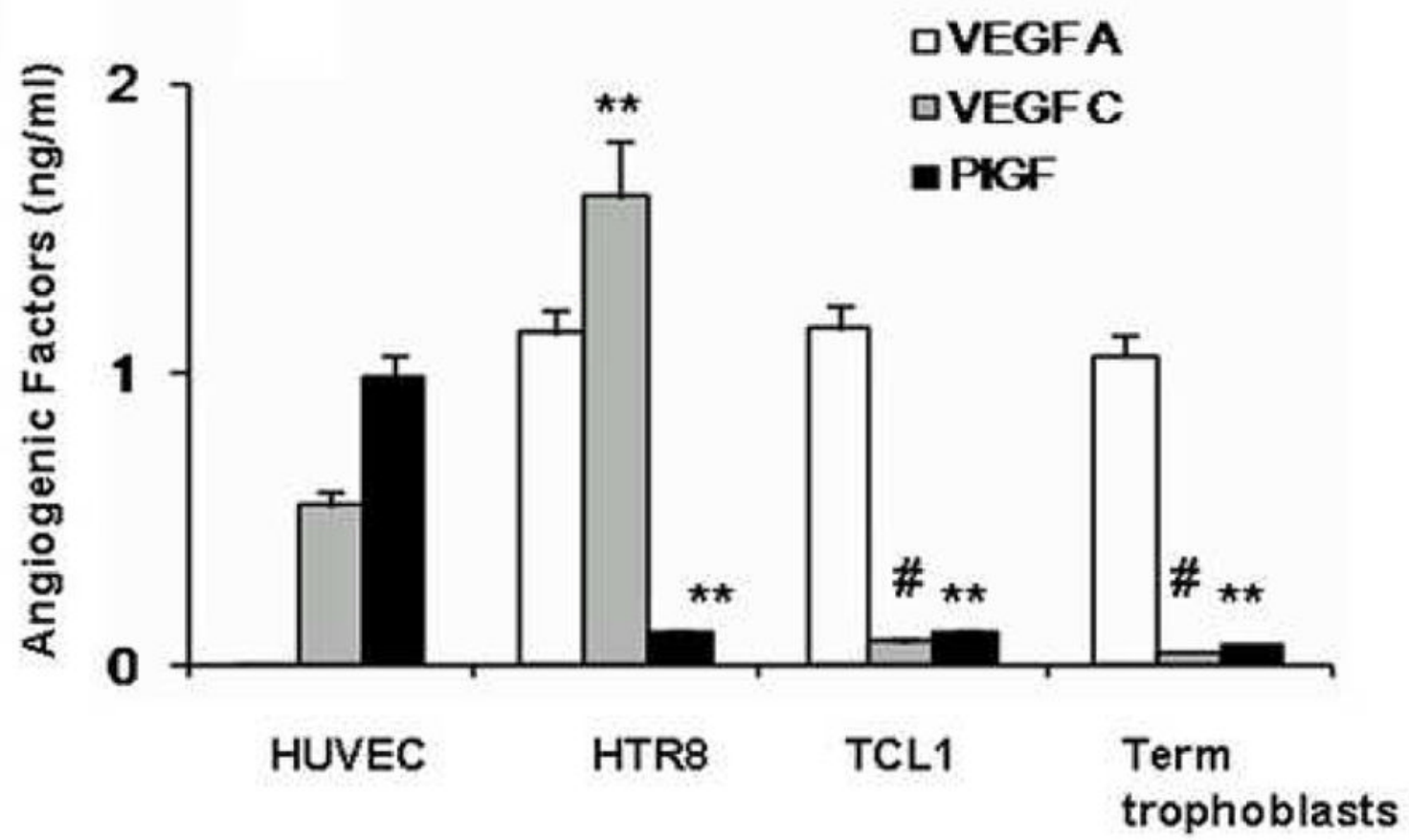

Figure 2. Term primary trophoblasts and TCL1 lack VEGF C expression

(A) Semi-quantitative RT-PCR using total RNA from HUVEC and trophoblasts was performed to evaluate the expression of VEGF A and VEGF $C$ using $\beta$-actin as a loading control. This figure is representative of three different experiments. (B) Conditioned media from HUVEC and trophoblast cells were evaluated for angiogenic factors by ELISA and expressed as mean \pm SD. $* *$ and ${ }^{*} \mathrm{P}<0.05$ as compared with HUVEC and HTR8 pair and the HTR8 and TCL1 pair, respectively. 


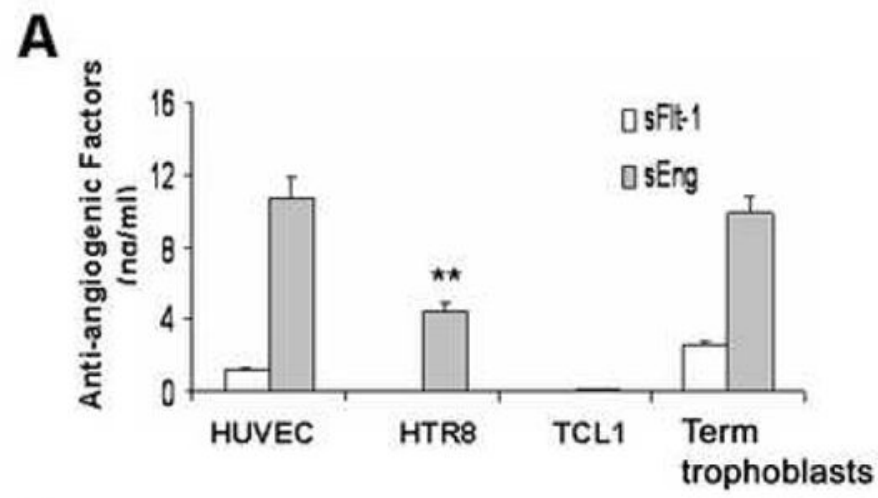

B
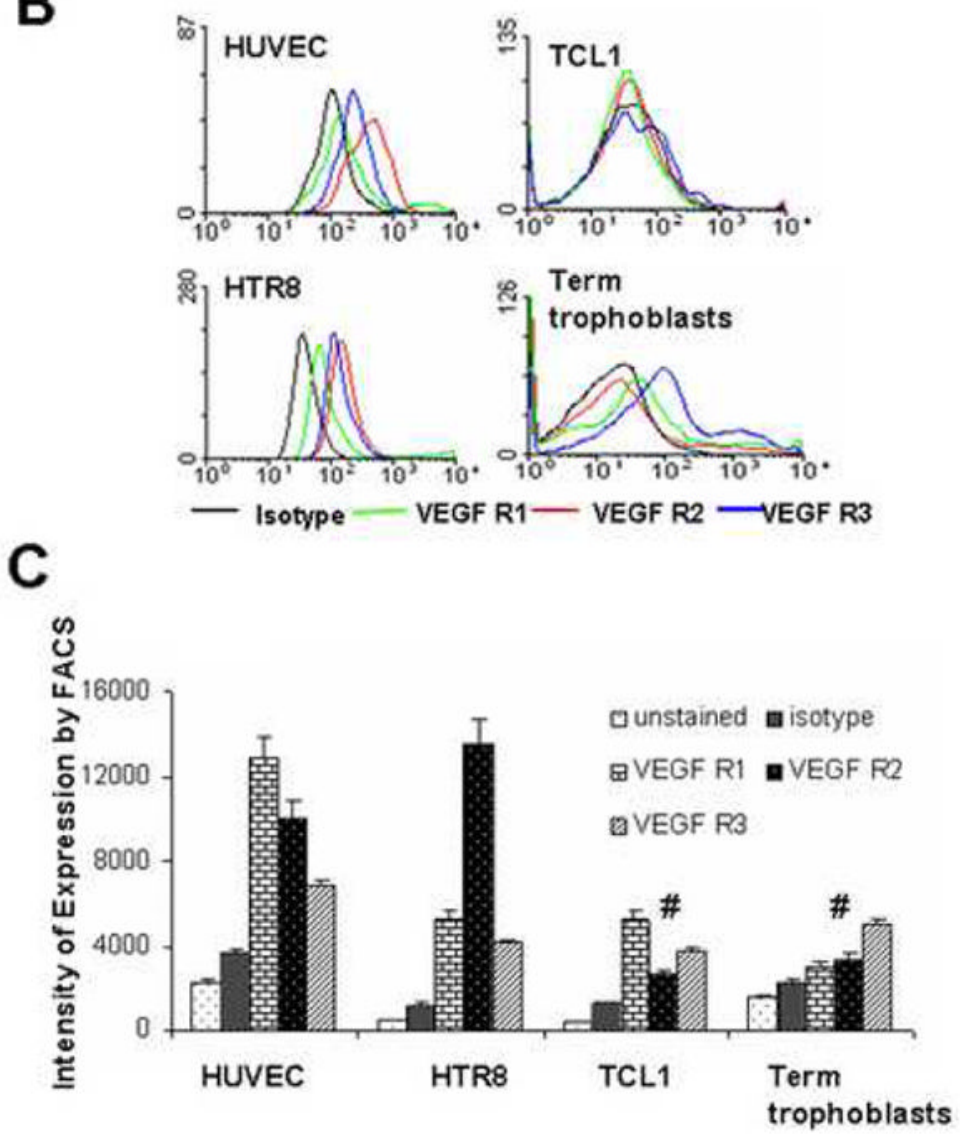

Figure 3. Anti-angiogenic factors and lack of VEGF receptors contribute to poor interaction by term trophoblasts

(A) Supernatants from cultured EC and trophoblasts were evaluated for sFlt-1 and sEng by ELISA and the values are expressed as mean \pm SD from triplicate assays. (B) VEGF receptor expression profiles are shown for HUVEC, HTR8, TCL1, and term primary trophoblasts. (C) Quantitative analysis for FACS data represents the mean intensity from three different experiments and is shown with standard deviation (bars, $\pm \mathrm{SD}$ ). * and ${ }^{\#} \mathrm{P}<0.05$ for the HUVEC and HTR8 pair and the HTR8 and TCL1 pair, respectively. 
A

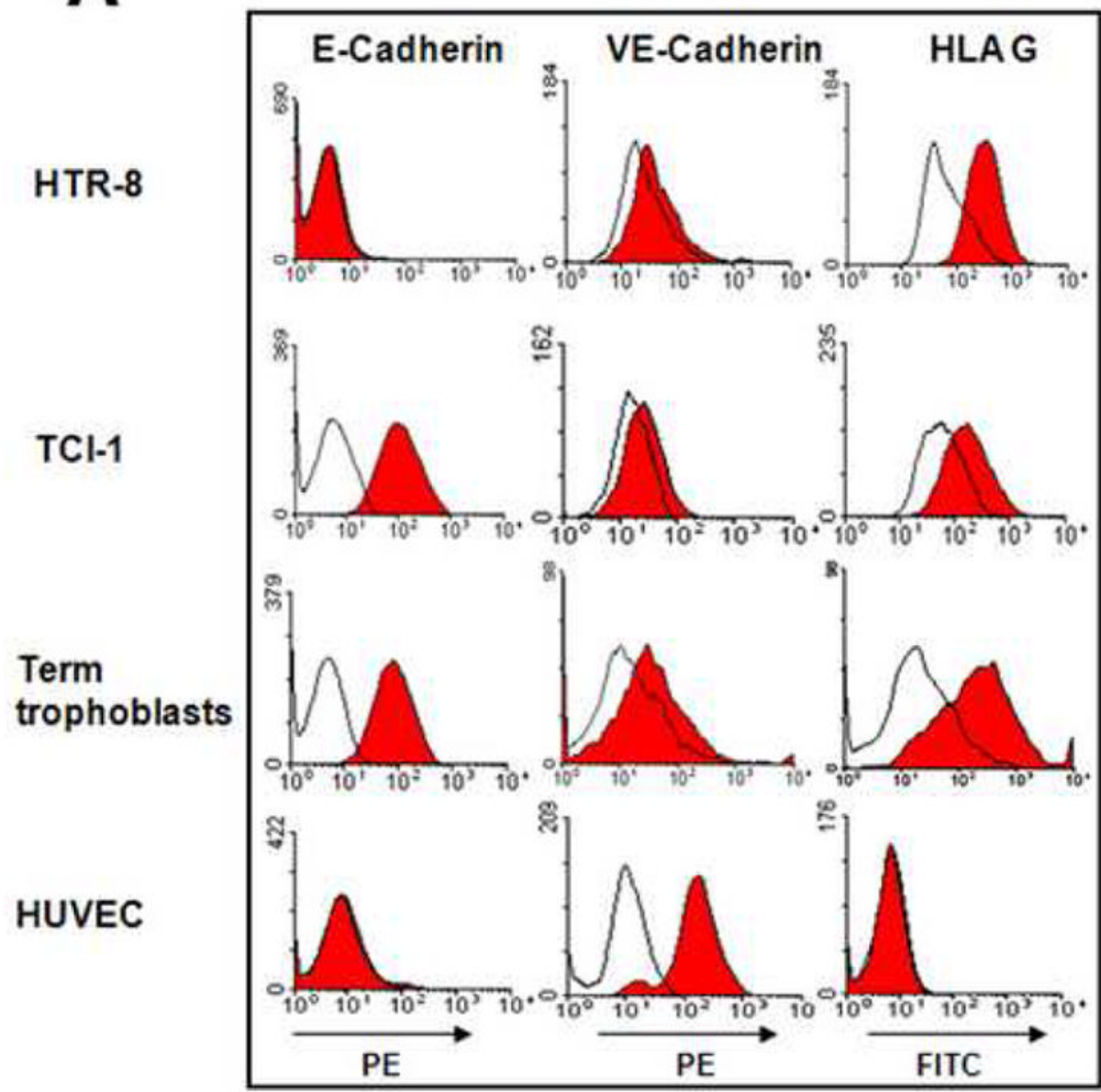

B

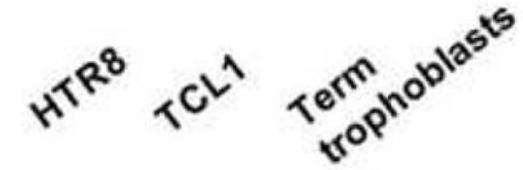

E-cadherin

$\beta$-Actin

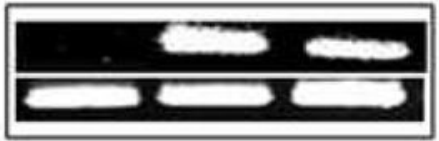

Figure 4. E-cadherin expression contributes to poor endovascular activity of TCL1 and primary term trophoblasts

(A) FACS analysis of E-cadherin, VE-cadherin and HLA G. (B) RT-PCR analysis of Ecadherin expression in HTR8, TCL1 and primary term trophoblasts. Intense expression of Ecadherin is observed in third trimester trophoblast cell line TCL1 and primary term trophoblasts but not in first trimester HTR8 cells. A representative of three independent experiments is shown. 

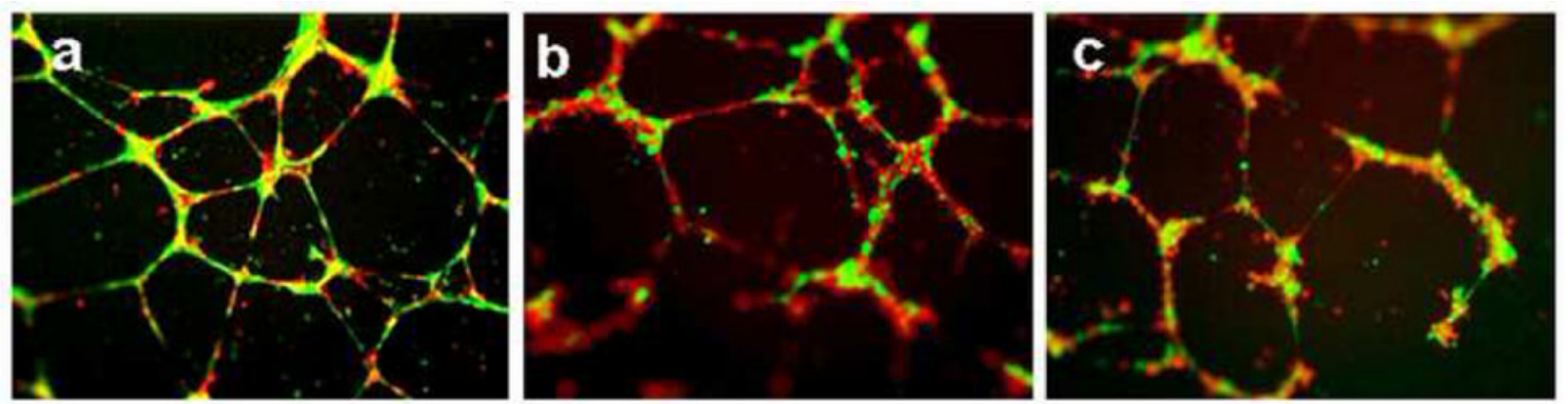

Figure 5. Functional VEGF R2 is essential for endothelial-trophoblast interaction

HTR8 cells were pre-incubated with VEGF R2 kinase inhibitor SU1498 at $10 \mu \mathrm{M}$ (b) or 20 $\mu \mathrm{M}$ (c) and then co-cultured on matrigel with HUVEC cells. Tube formation was evaluated and compared to untreated control HTR8 and EC (a). Pretreatment of HTR8 cells with SU1498 blocks their participation in tube formation. A representative from three independent experiments is shown. 

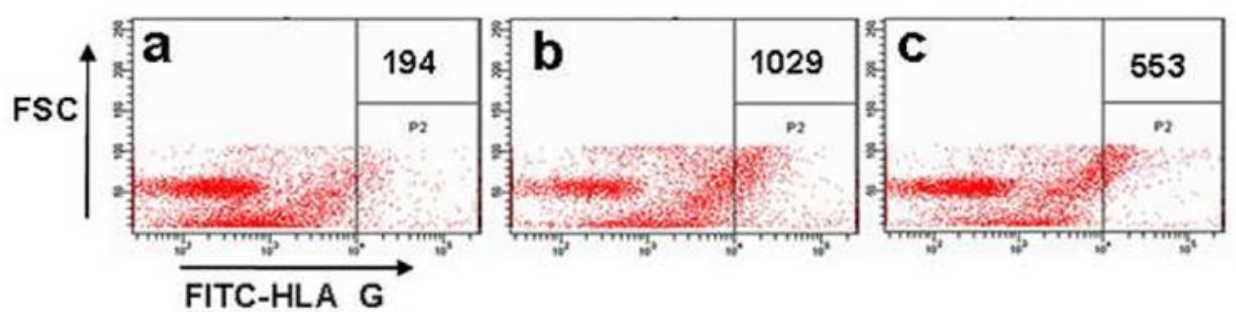

HTR8

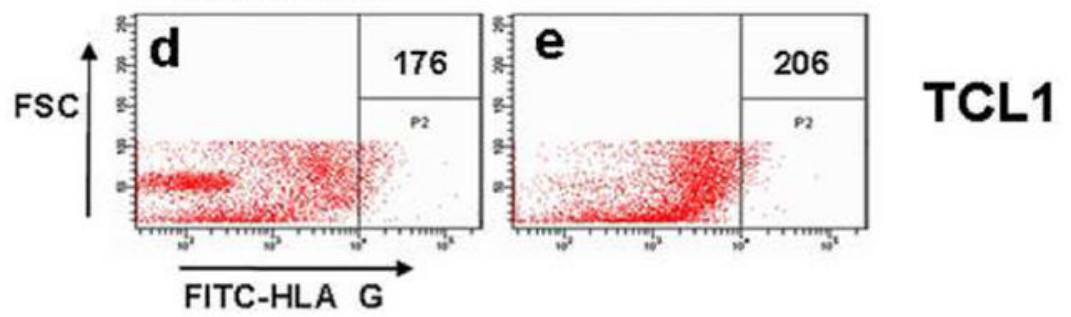

Figure 6. In vivo matrigel plug assay for trophoblast-endothelial cell interactions

Nude mice ( $n=3$ per group)) were injected s.c. with matrigel with or without HUVEC cells. HTR8 or TCL1 trophoblasts were injected around the rim after 30 minutes. Representative quantitative FACS analysis of $\mathrm{HLA} \mathrm{G}^{+}$trophoblasts entrapped in HUVEC containing plug is indicated at the corner of each panel. (a) Control matrigel (no cells) $+\mathrm{HTR} 8$, (b) Matrigelentrapped HUVEC+HTR8, (c) Matrigel-entrapped HUVEC+SU1498-treated HTR8, (d) Control matrigel+TCL1, and (f) Matrigel-entrapped HUVEC+TCL1. 